\title{
Estimativa do fluxo de calor latente pelo balanço de energia em cultivo protegido de pimentão(1)
}

\author{
Antonio Ribeiro da Cunha( ${ }^{(2)}$, João Francisco Escobedo(2) e Elcio Silvério Klosowski(2)
}

\begin{abstract}
Resumo - O objetivo deste trabalho foi caracterizar e relacionar a radiação líquida com o calor latente equivalente, em mm de água, nos cultivos protegido e de campo, na cultura de pimentão. O experimento foi feito em Botucatu, SP. A estimativa do fluxo de calor latente foi feita pelo método do balanço de energia, por meio da razão de Bowen. Foram feitas medidas instantâneas da radiação líquida (Rn), dos fluxos convectivos de calor latente (LE) e sensível (H), do fluxo de calor no solo (G), e dos gradientes psicrométricos sobre a cultura. $\mathrm{O}$ cultivo protegido, apesar de receber menor quantidade de radiação solar global, foi mais eficiente na conversão da radiação líquida disponível em matéria seca total e na produtividade de frutos. No balanço de energia, o cultivo protegido apresentou razões G/Rn e LE/Rn inferiores e $\mathrm{H} / \mathrm{Rn}$ superior, com um fluxo de calor latente, equivalente em milímetros, $45,43 \%$ menor que no cultivo no campo. Apresentou, ainda, menor quantidade de radiação líquida disponível e menores perdas de energia, mostrando-se mais eficiente no uso da água.
\end{abstract}

Termos para indexação: Capsicum annuum, energia solar, radiação térmica, evapotranspiração.

\section{Estimate of the latent heat flux by the energy balance in protected cultivation of sweet pepper}

\begin{abstract}
The aim of this work was to characterize and bring into relationship the net radiation with the latent heat flux equivalent to water $\mathrm{mm}$, in sweet pepper crops in the field and in protected cultivation. The estimate of latent heat flux was made by the energy balance method through the Bowen ratio. Instantaneous measures were made of net radiation $(\mathrm{Rn})$, sensitive $(\mathrm{H})$ and latent $(\mathrm{LE})$ heat fluxes, heat flux into the soil $(\mathrm{G})$, and of psychrometers gradients in the crop canopy. In protected cultivation, the conversion of the available net radiation in total dry matter and fruit productivity was more efficient than in the field, in spite of lower amounts of global solar radiation received by the crop. Ratios of G/Rn and LE/Rn were lower, and that of $\mathrm{H} / \mathrm{Rn}$ was higher in protected cultivation, with an equivalent latent heat flux in millimeters, $45.43 \%$ lower than that determined in the field. Available net radiation and energy losses were also lower in protected cultivation, showing a higher water use efficiency.
\end{abstract}

Index terms: Capsicum annuum, solar energy, thermal radiation, evapotranspiration.

\section{Introdução}

A água é um dos principais fatores limitantes da produção do pimentão. Na sua falta ocorrem redução no crescimento e desenvolvimento, na produtividade e qualidade dos frutos, e um maior desenvolvimento radicular com menor eficiência de absorção

\footnotetext{
(1) Aceito para publicação em 30 de outubro de 2001.

(2) Universidade Estadual Paulista, Faculdade de Ciências Agronômicas, Dep. de Recursos Naturais, Caixa Postal 237, CEP 18603-970 Botucatu, SP.

E-mail: arcunha@fca.unesp.br, escobedo@fca.unesp.br, esklosowski@unioeste.br
}

de nutrientes. Quando em excesso, aumenta a incidência de doenças, a lixiviação de nutrientes e a ocorrência de podridões-de-raízes (Caixeta, 1984; Casali \& Couto, 1984).

Segundo Doorenbos \& Kassan (1994), a cultura do pimentão é classificada como de sensibilidade média a alta ao suprimento de água durante todo o ciclo, e bastante sensível ao déficit hídrico do solo, sobretudo no início da floração, quando não deve utilizar mais do que $25 \%$ da água disponível.

No Brasil, a cultura de pimentão no campo, especificamente no Estado de São Paulo, atinge uma área de 2.749 ha, com uma produção total de $65.316 \mathrm{~kg}$ (Instituto de Economia Agrícola, 2001). 
A FAO estima que a evapotranspiração é reduzida em $30 \%$ nos cultivos protegidos, que o uso da água por unidade de produção pode ser diminuído em até $50 \%$, e que se tem maior produtividade em ambientes protegidos (Stanghellini, 1993). Em dois anos de pesquisa, Martins (1992) confirmou que a evaporação sob cobertura de plástico foi cerca de $30 \%$ menor do que no campo, o que contribuiu para um menor consumo de água da cultura no ambiente protegido.

$\mathrm{O}$ crescimento e a produtividade das plantas estão diretamente relacionados com a água, e a maior parte da água utilizada pelas plantas é vaporizada para a atmosfera pela transpiração. Essa energia, consumida no processo de evapotranspiração, tem origem na energia radiante e térmica oriundas da radiação solar.

Bowen (1926) foi o pioneiro nos estudos do balanço da energia sobre uma superfície natural, determinando a razão entre os fluxos de calor latente e sensível emitidos por uma superfície de água, durante o processo de evaporação, em função dos gradientes da pressão do vapor e da temperatura observados sobre a superfície, denominada razão de Bowen. Grande esforço da pesquisa tem sido concentrado na quantificação dos componentes do balanço de energia através da razão de Bowen, já considerado padrão para mensurar os fluxos convectivos de calor latente e sensível (Villa Nova, 1973; Alfonsi et al., 1986; Fontana et al., 1991; Cunha \& Bergamaschi, 1994; Cunha et al., 1996; Alves et al., 1998; Ávila Netto et al., 1999; Cunha, 2001).

O método do balanço de energia é considerado um processo racional de estimativa de evapotranspiração de uma superfície, o qual mede a energia disponível em um sistema natural e separa as frações usadas nos diferentes processos, obtendose, assim, bons resultados (Villa Nova, 1973). O conhecimento da evapotranspiração ou do fluxo convectivo de calor latente contribui para uma utilização mais racional da água em uma determinada cultura em que as fases críticas de desenvolvimento vegetativo e reprodutivo são limitadas pelo fator hídrico.

O objetivo deste trabalho foi caracterizar e relacionar a radiação líquida com o calor latente equivalente em mm de água, em cultivos protegido e de campo, na cultura do pimentão.

\section{Material e Métodos}

O experimento foi realizado no período de 21/4/99 a 3/11/99, na área experimental do Departamento de Recursos Naturais - Setor Ciências Ambientais, da Faculdade de Ciências Agronômicas, da Universidade Estadual Paulista (Unesp), Campus de Botucatu, Botucatu, SP (22 $51^{\circ}$ S de latitude, $48^{\circ} 26^{\prime} \mathrm{W}$ de longitude e $786 \mathrm{~m}$ de altitude). O clima é Cwa segundo W. Köppen, temperado-quente (mesotérmico) com chuvas no verão e seca no inverno, e com temperatura média do mês mais quente superior a $22^{\circ} \mathrm{C}$, com temperatura média anual de $20,5^{\circ} \mathrm{C}$ e precipitação pluvial média anual de 1.533,2 mm (Cunha et al., 1999). O cultivo protegido foi feito em uma estufa tipo arco, nãoclimatizada, e orientada no sentido NNW-SSE, constituída de estrutura de ferro galvanizado, área de $280 \mathrm{~m}^{2}(7,0 \mathrm{~m} \mathrm{x}$ $40,0 \mathrm{~m})$ e altura lateral de $2,2 \mathrm{~m}$ acima do nível do solo. A cobertura empregada foi uma película de polietileno transparente de baixa densidade (PEBD) de $120 \mu \mathrm{m}$ de espessura e com malha preta de polipropileno fixa, com redução de $50 \%$ da radiação solar nas paredes laterais. Foi demarcada uma área externa com as mesmas dimensões, para o cultivo de campo. A cultivar de pimentão utilizada foi a Elisa, a qual apresenta frutos vermelhos quando maduros. O transplantio foi realizado em 20/4/99 (33 dias após a semeadura), com uma planta por cova, no espaçamento de $0,3 \mathrm{~m}$ na linha por $1,0 \mathrm{~m}$ de canteiro. A área experimental foi constituída por três canteiros de $1 \mathrm{~m}$ de largura e $36 \mathrm{~m}$ de comprimento, com apenas uma fileira de cultura por canteiro, com 120 plantas por canteiro, totalizando 360 plantas, nos dois ambientes. A adubação foi feita com base na análise química de solo, e os adubos foram incorporados nos canteiros, a uma profundidade de 25 a $30 \mathrm{~cm}: 3,0 \mathrm{~kg} / \mathrm{m}^{2}$ de esterco bovino decomposto, $100 \mathrm{~g} / \mathrm{m}^{2}$ da fórmula 4-14-8, e $150 \mathrm{~g} / \mathrm{m}^{2}$ de termofosfato Yoorin BZ. Em cobertura, foram aplicados $8,0 \mathrm{~g}$ por planta de nitrocálcio aos 20 dias após o transplantio, repetindo-se essa operação por mais quatro vezes, com um intervalo de 20 dias entre cada aplicação. O controle de plantas daninhas foi feito por meio de seis capinas manuais ao longo do ciclo. Tanto o controle de pragas quanto o de doenças foi efetuado mediante exame visual do agente, inseto ou patógeno, e de acordo com recomendações técnicas do produto químico para cada caso.

O sistema de irrigação utilizado nos dois cultivos foi o de tubos gotejadores, trabalhando com 5,0 m.c.a. (metro de coluna d'água) e vazão de $1,0 \mathrm{~L} / \mathrm{h}$ por gotejador. $\mathrm{O}$ espaçamento entre os gotejadores na linha de plantio foi de $0,30 \mathrm{~m}$. O controle das irrigações foi feito com base na aplicação do balanço de energia, pela estimativa do fluxo convectivo de calor latente equivalente em $\mathrm{mm}$ (ET) do dia anterior para sua posterior reposição. Para isso, 
correlacionou-se a vazão dos tubos gotejadores ( $\mathrm{mm}$ ) com o tempo (minutos), para estimar o tempo de irrigação (Tempo). Pelos valores de ET estimados no dia anterior, foi possível repor a lâmina de água evaporada na superfície do solo, pela expressão:

Tempo $=9,461($ ET $)$,

em que: Tempo é o tempo de irrigação em minutos; ET é o fluxo de calor latente equivalente em milímetros.

$\mathrm{O}$ balanço de energia foi determinado segundo a razão de Bowen (1926), e a equação geral do balanço de energia foi descrita da seguinte forma:

$\mathrm{Rn}-\mathrm{G}-\mathrm{H}-\mathrm{LE}=0$, ou seja: $\mathrm{Rn}=\mathrm{G}+\mathrm{H}+\mathrm{LE}$

em que: Rn é a radiação líquida disponível sobre a superfície da cultura em $\mathrm{W} / \mathrm{m}^{2} ; \mathrm{G}$, o fluxo de calor no solo em $\mathrm{W} / \mathrm{m}^{2} ; \mathrm{H}$, o fluxo de calor sensível em $\mathrm{W} / \mathrm{m}^{2}$; LE, o fluxo de calor latente em $\mathrm{W} / \mathrm{m}^{2}$.

No cálculo do balanço de energia, os fluxos que chegavam ao sistema (cultura do pimentão) foram considerados positivos, e os que saíam negativos; e o ápice da cultura e a superfície do solo foram considerados os limites superior e inferior do sistema, respectivamente.

A radiação líquida $(\mathrm{Rn})$ correspondeu à energia disponível no sistema analisado, ou seja, constituiu a diferença entre os fluxos totais da radiação incidente e refletida pela superfície da cultura. $\mathrm{O}$ fluxo de calor sensível $(\mathrm{H})$ foi o calor destinado ao aquecimento do ar atmosférico. O fluxo de calor latente (LE) foi o calor utilizado na mudança de fase da $\mathrm{H}_{2} \mathrm{O}$ da forma líquida para gasosa, sendo considerada a energia subtraída da superfície do solo. O fluxo de calor no solo $(\mathrm{G})$ foi representado pela fração da $\mathrm{Rn}$ que foi transmitida para o interior do solo a $0,02 \mathrm{~m}$ de profundidade, dependente da radiação solar global e da condutividade térmica do solo.

Utilizou-se a razão de Bowen para a estimativa dos fluxos $\mathrm{H}$ e LE, por meio das medições de gradientes psicrométricos na cultura, entre dois níveis, com uma distância de $0,50 \mathrm{~m}$ entre o conjunto de psicrômetros de termopar do bulbo seco e úmido (níveis), sendo o primeiro nível instalado a 1,0 $\mathrm{m}$ de altura da superfície do solo, e o segundo, a 1,5 m de altura, conforme as equações (3), (4) e (5):

$\beta=\frac{H}{\mathrm{LE}}=\frac{1}{\left(\frac{\mathrm{s}+\gamma}{\gamma}\right)\left(\frac{\Delta \mathrm{T}_{\mathrm{U}}}{\Delta \mathrm{T}}\right)-1}$,

$\mathrm{LE}=\frac{(\mathrm{Rn}-\mathrm{G})}{(1+\beta)}$,

em que: $\beta$ é a razão de Bowen; s, a tangente à curva de pressão de saturação de vapor d'água em função da temperatura do $\operatorname{ar}\left(\mathrm{kPa} /{ }^{\circ} \mathrm{C}\right)$, dada pela expressão:
$\mathrm{s}=\frac{4098}{\left(\mathrm{~T}_{\mathrm{S}}+237,3\right)^{2}} \mathrm{e}_{\mathrm{S}}\left(\mathrm{T}_{\mathrm{S}}\right)$

em que: $T_{\mathrm{s}}$ é a temperatura média do bulbo seco entre os dois níveis $\left({ }^{\circ} \mathrm{C}\right)$; $\mathrm{e}_{\mathrm{s}}$ é a pressão de saturação de vapor d'água à temperatura de bulbo seco em $\mathrm{kPa} ; \gamma$, o coeficiente psicrométrico igual a $0,0725 \mathrm{kPa} /{ }^{\circ} \mathrm{C}$, para uma pressão atmosférica de $90,66 \mathrm{kPa}$ e constante pscicrométrica de $80.10^{-5} /{ }^{\circ} \mathrm{C} ; \Delta \mathrm{T}_{\mathrm{U}}$, a diferença das leituras dos termopares úmidos instalados entre os dois níveis considerados; $\Delta \mathrm{T}$, a diferença das leituras dos termopares secos instalados entre os dois níveis considerados.

Foram utilizados termopares de cobre-constantan calibrados a $0^{\circ} \mathrm{C}$ e $100^{\circ} \mathrm{C}$, ou seja, para os pontos de gelo fundente e água em ebulição, respectivamente, para o monitoramento das temperaturas de bulbo seco e úmido, constando, ao todo, de quatro conjuntos psicrométricos, isto é: dois instalados no cultivo protegido, e dois no campo, utilizando-se para a temperatura de referência um sensor Vaisala modelo HMP45C instalado num abrigo modelo UT12VA. Foram obtidos valores de calibração para os termopares, em média de $0,3^{\circ} \mathrm{C}$ e $99,8^{\circ} \mathrm{C}$, para o ponto de gelo fundente e água em ebulição, respectivamente. Esses conjuntos psicrométricos de termopares de bulbo seco e úmido foram introduzidos em microabrigos confeccionados em acrílico, com aeração natural e protegidos contra radiação direta e parte da difusa. Os conjuntos de microabrigos de acrílico foram instalados eqüidistantes um do outro, sendo o primeiro nível instalado a 1,0 $\mathrm{m}$ de altura em relação à superfície do solo, e o segundo, a 1,5 m. $\mathrm{O}$ funcionamento desses microabrigos foi verificado pela correlação de suas medidas com as de um sensor de temperatura e umidade relativa do ar Vaisala modelo HMP45C (Cunha, 2001).

A $\mathrm{Rn}$ foi medida por meio de dois saldos radiômetros modelo Q7.1 (REBS), instalados a dois metros de altura. $\mathrm{O} G$ foi medido por dois fluxímetros modelo HFT-3 (REBS), instalados a $0,02 \mathrm{~m}$ de profundidade da superfície do solo, próximos à linha de plantio da cultura. Um dos sensores foi instalado no cultivo protegido, e outro, no cultivo de campo.

Os sensores que monitoraram a Rn, o G e os psicrômetros de termopares, foram conectados a um sistema de aquisição automática, um "Micrologger 21X”, e programados por meio de linguagem específica com varredura dos sensores a cada cinco segundos, e saída média dos dados a cada cinco minutos, e transferidos para um módulo externo de expansão de memória RAM, modelo SM192. Esses dados foram transferidos para um microcomputador através de interface modelo SC532, para posterior confecção de curvas diárias dos valores instantâneos $\left(\mathrm{W} / \mathrm{m}^{2}\right)$ da radiação líquida, dos fluxos convectivos de calor latente e 
sensível, do fluxo de calor no solo, e posterior integralização dos seus valores ao longo do dia em $\mathrm{MJ} / \mathrm{m}^{2}$.

Em ambos os cultivos, a duração do ciclo da cultura foi de 195 dias após o transplantio (DAT), definido pelo final da fase de produção de frutos. As plantas foram conduzidas com três hastes, a partir da primeira bifurcação, e, a partir daí, foram feitas as desbrotas semanalmente, para a condução destes três ramos apenas. A colheita dos frutos foi individualizada em doze plantas marcadas da área experimental, a saber: seis em cultivo protegido, e seis no campo, e feitas semanalmente quando os frutos atingiram em torno de $60 \%$ da coloração vermelha. O período da colheita foi de nove semanas (7/9/99 a 3/11/99).

As análises de crescimento foram feitas extraindo-se quatro plantas da área experimental a cada 15 dias, duas do cultivo protegido, e duas do campo, tendo início a coleta para essas análises em 20/4/99, momento do transplantio. As análises constaram da altura, da área foliar, do índice de área foliar e da matéria seca total da planta (folhas, caules, raízes e frutos); os resultados foram originados da média de duas plantas, e convertidos para $1 \mathrm{~m}^{2}$, em cada cultivo.

Para fins de arranjo experimental, considerou-se como sendo um delineamento inteiramente casualizado.

A altura das plantas $(\mathrm{cm})$ foi medida individualmente, a partir da superfície do solo, até o ápice da planta. A medição da área foliar $\left(\mathrm{cm}^{2}\right)$ foi feita com um medidor foliar modelo CI 202 (USA), em todas as folhas de cada planta.

$\mathrm{O}$ índice de área foliar (IAF) foi determinado pela relação entre a área foliar $\left(\mathrm{m}^{2}\right)$ das plantas contidas em $1 \mathrm{~m}^{2} \mathrm{de}$ área. A matéria seca total (MST) da planta foi obtida após as folhas, caule, ramos, raízes e frutos serem levados a uma estufa aerada a $100^{\circ} \mathrm{C}$, por 48 horas, para secagem, e pesados em balança BEL, modelo 8040, com precisão de duas casas. A produtividade foi obtida a partir da média da produção de frutos de seis plantas, em $\mathrm{kg} /$ planta, através da expressão (6), em kg/m²:

Produtividade $=(\mathrm{kg} / \mathrm{planta}) 3,33$.

A eficiência do uso da água para a produtividade de frutos foi obtida pela relação entre o peso dos frutos em $\mathrm{kg} / \mathrm{m}^{2}$ e o fluxo de calor latente equivalente em milímetros (ET), durante o ciclo da cultura do pimentão, obtendose o seu valor em $\mathrm{kg} / \mathrm{m}^{2} / \mathrm{mm}$.

\section{Resultados e Discussão}

A variação média da radiação líquida $(\mathrm{Rn})$ a cada 15 dias na cultura de pimentão demonstra que o cultivo protegido dispôs de menos energia para o seu crescimento e desenvolvimento (Figura 1 e Tabela 1).
Quanto à matéria seca total (MST) de plantas da cultura de pimentão, as diferenças iniciaram aos 45 DAT e foram crescentes até o final do ciclo, com os maiores valores para o cultivo protegido (Figura 1). As diferenças na matéria seca total são maiores que em altura de plantas, entre os dois cultivos, em razão dos respectivos valores da média e do desvio-padrão. Isto ocorreu pelo fato de o índice da área foliar (IAF) ser maior no cultivo protegido, pois logo a partir dos 30 DAT até o final do ciclo, o IAF apresentou os maiores valores (Figura 1 e Tabela 1).

Aos 15 e 30 DAT as diferenças na altura das plantas são pequenas, e aos 45 DAT as diferenças passaram a ser acentuadas e crescentes até atingir a altura máxima, nas duas condições de cultivo, e os maiores valores ocorreram no cultivo protegido (Figura 1). Resultados semelhantes aos da cultura de pimentão em cultivo protegido foram obtidos por Teodoro (1986), Faria Júnior (1997) e Santos et al. (1999). Especificamente em relação ao híbrido Elisa, as alturas das plantas ficaram entre 80 e $90 \mathrm{~cm}$ no ambiente protegido (Panelo, 1995; Tivelli, 1999).

O cultivo protegido, apesar de ter tido menos energia líquida disponível (Rn) para o crescimento e desenvolvimento da cultura de pimentão, apresentou maior altura de plantas, maior quantidade de matéria seca total, e, conseqüentemente, maior índice de área foliar durante todo o ciclo, comprovado pelos respectivos valores médios e do desvio-padrão (Tabela 1).

A radiação líquida disponível na cultura de pimentão ao longo do ciclo foi de $1.441,18 \mathrm{MJ} / \mathrm{m}^{2} / \mathrm{ci}$ clo, com uma produtividade de $9,29 \mathrm{~kg} / \mathrm{m}^{2}$ no cultivo protegido, enquanto no cultivo de campo foi de $1.879,33 \mathrm{MJ} / \mathrm{m}^{2} /$ ciclo, com uma produtividade de $6,66 \mathrm{~kg} / \mathrm{m}^{2}$. Neste caso, o cultivo protegido foi mais eficiente por $\mathrm{kg}$ de fruto produzido em $1 \mathrm{~m}^{2}$, em relação à radiação líquida disponível $(\mathrm{Rn})$ em $\mathrm{MJ}$, pois apresentou uma relação $\mathrm{Rn} /$ Produtividade de $155,13 \mathrm{MJ} / \mathrm{kg} /$ ciclo e $282,18 \mathrm{MJ} / \mathrm{kg} /$ ciclo, no cultivo protegido e de campo, respectivamente. Com relação à matéria seca total, os resultados mostraram, ao longo do ciclo, produção acumulada de $3.074,52 \mathrm{~g} / \mathrm{m}^{2} /$ ciclo e de $1.773,16 \mathrm{~g} / \mathrm{m}^{2} /$ ciclo, no cultivo protegido e de campo, respectivamente. A relação $\mathrm{MST} / \mathrm{Rn}$, obtida no cultivo protegido e de campo, foi de 2,13 g/MJ/ciclo e de $0,94 \mathrm{~g} / \mathrm{MJ} /$ ciclo, respecti- 
vamente, o que mostra que o cultivo protegido superou em $227 \%$ o cultivo de campo, pois produziu mais matéria seca total utilizando-se de menos radiação líquida em 1 m². Tivelli (1999), em São Manuel, SP, utilizando-se de ambiente protegido, obteve uma produtividade da cultura de pimentão (híbrido Elisa) de $3,5 \mathrm{~kg} / \mathrm{m}^{2}$.

No balanço de energia do cultivo protegido, a radiação líquida $(\mathrm{Rn})$ representou $2,05 \%$ do fluxo de calor no solo (G) $\left(29,61 \mathrm{MJ} / \mathrm{m}^{2} /\right.$ ciclo), $87,74 \%$ do fluxo de calor latente (LE) $\left(1.264,46 \mathrm{MJ} / \mathrm{m}^{2} /\right.$ ciclo), e $9,66 \%$ do fluxo de calor sensível $(\mathrm{H})\left(139,25 \mathrm{MJ} / \mathrm{m}^{2} /\right.$ ciclo $)$ do fluxo de energia radiante disponível. No cultivo de campo, a $\mathrm{Rn}$ representou $6,61 \%$ do $\mathrm{G}$ (124,17 MJ $/ \mathrm{m}^{2} /$ ciclo), $98,04 \%$ do LE $\left(1.842,49 \mathrm{MJ} / \mathrm{m}^{2} /\right.$ ciclo), e 4,02\% do H (-75,50 MJ/m²/ciclo) do fluxo de energia radiante disponível (Tabela 2). Souza (1996) encontrou razões desta proporção em ambiente protegido com cobertura de polietileno transparente de $100 \mu \mathrm{m}$, cultivado com feijão-vagem, de 79\%,19\% e $2 \%$, e no cultivo de campo, de $68 \%, 31 \%$ e $2 \%$ em relação às razões $\mathrm{LE} / \mathrm{Rn}, \mathrm{H} / \mathrm{Rn} \mathrm{e} \mathrm{G} / \mathrm{Rn}$, respectivamente.

Segundo Lemon et al. (1971), a Rn fica distribuída de 40 a $90 \%$ no LE, de 10 a $60 \%$ para o He de 5 a $10 \%$ para o G. No cultivo do milho (Alfonsi et al., 1986; Cunha et al., 1996), do feijão (Bergamaschi et al., 1988), da alfafa (Cunha \& Bergamaschi, 1994), do melão (Alves et al., 1998), da grama (Silva et al., 1999) e da videira (Ávila Netto et al., 1999), utilizaram a razão de Bowen para a estimativa dos fluxos $\mathrm{H}$ e LE nessas diferentes culturas em condições de campo, obtendo razões LE/Rn, H/Rn e G/Rn das mais diversas proporções, tornando difícil a comparação entre elas, em face dos seguintes fatores que ocorrem nes-
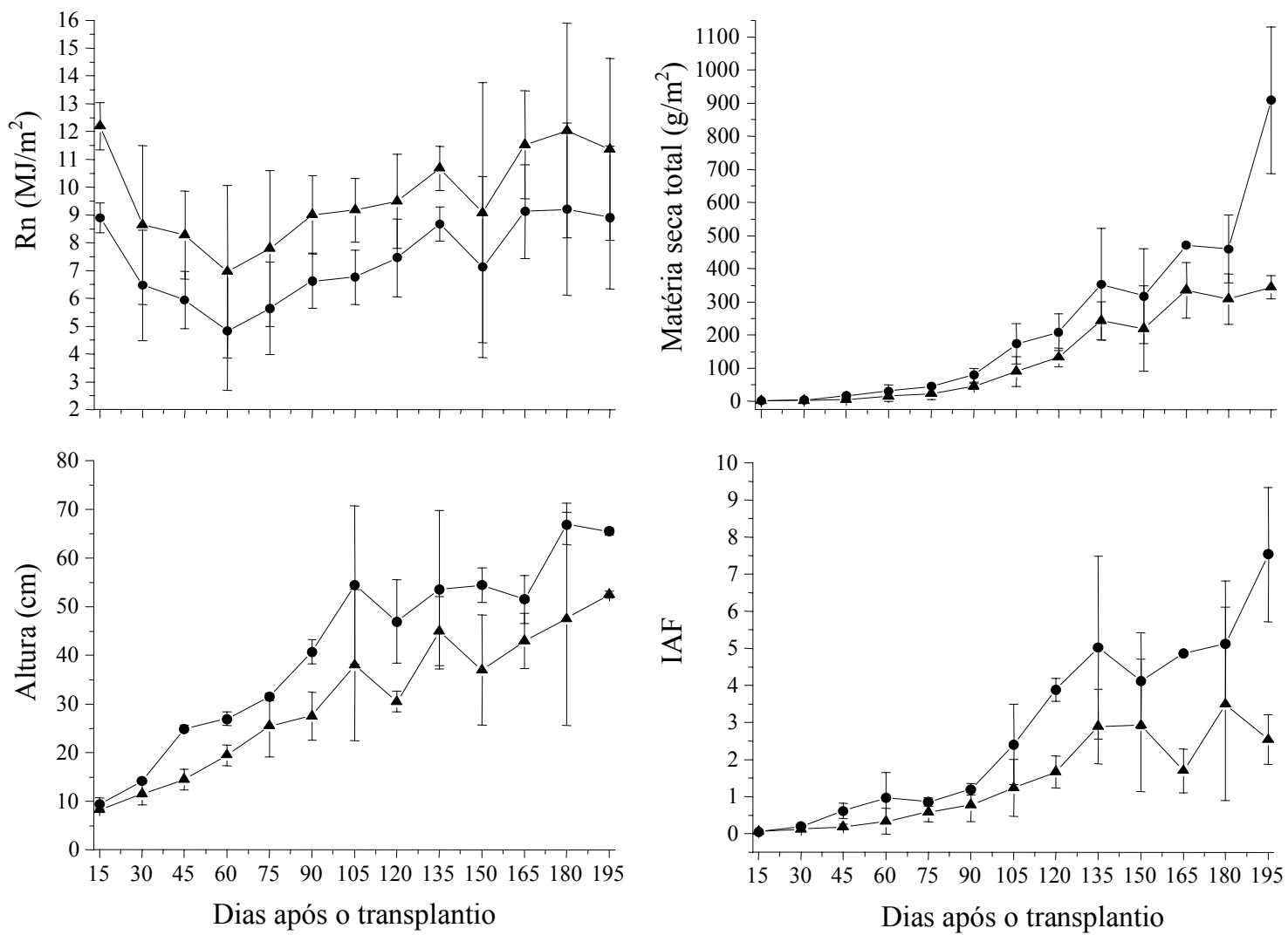

Figura 1. Radiação líquida (Rn), matéria seca total, altura das plantas e índice de área foliar (IAF) sob cultivo protegido (O) e de campo $(\mathbf{\Delta})$, com os respectivos desvios-padrão, avaliados a cada 15 dias, até os 195 dias após o transplantio da cultura do pimentão. 
Tabela 1. Média e desvio-padrão da radiação líquida (Rn), matéria seca total (MST), altura de plantas (ALT) e índice de área foliar (IAF) sob cultivo protegido e de campo, avaliados aos 195 dias após o transplantio da cultura do pimentão ${ }^{(1)}$.

\begin{tabular}{lcccc}
\hline Cultivo & $\begin{array}{c}\mathrm{Rn} \\
\left(\mathrm{MJ} / \mathrm{m}^{2}\right)\end{array}$ & $\begin{array}{c}\text { MST } \\
\left(\mathrm{g} / \mathrm{m}^{2}\right)\end{array}$ & $\begin{array}{c}\text { ALT } \\
(\mathrm{cm})\end{array}$ & IAF \\
\hline Protegido & $8,91(2,57)$ & $909,16(221,43)$ & $65,50(0,71)$ & $7,53(1,80)$ \\
Campo & $11,37(3,26)$ & $344,87(35,63)$ & $52,50(0,71)$ & $2,54(0,67)$ \\
\hline
\end{tabular}

(1)Número entre parênteses indica o desvio-padrão da média.

te tipo de estudo: a) a arquitetura da espécie da cultura estudada apresenta-se de forma diferenciada, alterando as medidas; b) local e condições atmosféricas distintas, por exemplo, céu limpo ou nublado, presença de vento; c) período de análise dos dados medidos e estimados, o que altera o balanço por causa da sazonalidade; d) instrumental utilizado para a medida dos gradientes psicrométricos sobre a cultura, ou seja, o tipo de psicrômetro (ventilação forçada ou natural), a altura dos psicrômetros entre os níveis analisados, a estabilização da temperatura no momento da leitura do termômetro de bulbo úmido, e o adequado suprimento de água para o termômetro de bulbo úmido; e) tipo de ambiente protegido; f) tipo de cobertura do teto e das laterais do ambiente protegido.

Os valores obtidos dos fluxos G, LE e H demonstram que houve diferenças entre os dois cultivos, mostrando que os fluxos acompanharam a disponibilidade energética na superfície; o cultivo protegido apresentou uma energia líquida disponível 30,40\% menor em relação ao cultivo no campo (Tabela 2). As razões G/Rn, LE/Rn e H/Rn obtidas, revelaram que houve maiores perdas de energia no cultivo de campo em relação ao cultivo protegido, tanto no que se refere à evaporação da água, quanto em relação ao aquecimento do ar próximo à superfície; atribuem-se essas perdas ao maior efeito advectivo do vento no cultivo de campo. Além disso, o fluxo LE apresentou-se maior em relação aos demais fluxos, em ambos os cultivos, comprovando a constante presença de advecção (Lemon et al., 1971; Alves et al., 1998). O valor negativo de $\mathrm{H}$ no cultivo de campo indica perda de calor da cultura para a atmosfera, em virtude do maior efeito advectivo, ou seja: a cultura estava mais aquecida que a atmosfera.

A curva do LE apresentou variação semelhante à curva da Rn, e houve alguns dias em que o LE supe-
Tabela 2. Partição do balanço de energia em cultivo protegido e de campo durante o ciclo da cultura de pimentão(1).

\begin{tabular}{lcc}
\hline Partição & $\begin{array}{c}\text { Protegido } \\
\left(\mathrm{MJ} / \mathrm{m}^{2} / \text { ciclo }\right)\end{array}$ & $\begin{array}{c}\text { Campo } \\
\left(\mathrm{MJ} / \mathrm{m}^{2} / \text { ciclo }\right)\end{array}$ \\
\hline $\mathrm{Rn}$ & $1.441,18$ & $1.879,33$ \\
$\mathrm{G}$ & 29,61 & 124,17 \\
$\mathrm{LE}$ & $1.264,46$ & $1.842,49$ \\
$\mathrm{H}$ & 139,25 & $-75,50$ \\
\hline $\mathrm{G} / \mathrm{Rn}$ & 0,02 & 0,07 \\
$\mathrm{LE} / \mathrm{Rn}$ & 0,88 & 0,98 \\
$\mathrm{H} / \mathrm{Rn}$ & 0,10 & $-0,04$ \\
\hline
\end{tabular}

${ }^{(1)} \mathrm{Rn}$ : radiação líquida; G: fluxo de calor no solo; LE: fluxo de calor latente; H: fluxo de calor sensível.

rou a Rn. No cultivo protegido, Rn apresentou um valor integrado menor, pelo fato de a transmissividade à radiação solar global do polietileno transparente de baixa densidade (PEBD) utilizado, ser de $68,81 \%$ (Cunha, 2001) (Figura 2).

$\mathrm{O} G$ no cultivo protegido apresentou um valor integrado menor $\left(29,61 \mathrm{MJ} / \mathrm{m}^{2} /\right.$ ciclo) do que no cultivo no campo $\left(124,17 \mathrm{MJ} / \mathrm{m}^{2} /\right.$ ciclo), indicando, assim, que ocorreu menor perda de calor no solo no cultivo protegido. $\mathrm{O} G$ variou menos na condição de cultivo protegido, pois as plantas se desenvolveram mais, apresentando um dossel mais denso após os 75 DAT, e a partir daí houve um maior sombreamento do solo nessa condição, com o sensor estando instalado na linha de plantio da cultura. Além disso, a cobertura de PEBD transparente utilizado diminuiu a radiação solar global, causando, assim, uma diminuição de energia disponível na superfície do solo no período diurno, por efeito da contra-irradiação do PEBD transparente. O cultivo protegido recebeu, em média, menos radiação solar global durante todo o ciclo da cultura de pimentão em relação ao cultivo no campo. Em conseqüência, o gradiente de calor no solo durante o dia foi menor, apresentando condições mais favoráveis de temperatura na superfície 
do solo para o crescimento e desenvolvimento da cultura (Figura 2).

Nas duas condições de cultivo, a demanda de energia para o LE superou a demanda para o $\mathrm{H}$, e no cultivo no campo essa demanda foi maior, tendo como causa os maiores efeitos convectivo e advectivo. Os valores de LE foram inferiores ao Rn em 13,98\% e $2,00 \%$, nos cultivos protegido e no campo, respectivamente, o que significa que, no cultivo protegido, o calor utilizado para a evaporação da água foi bem menor em relação ao disponível (Rn), propiciando uma maior economia de água pela cultura. Com relação ao H no cultivo de campo, os valores foram negativos, cedendo calor sensível da cultura para o aquecimento da atmosfera, enquanto no cultivo pro-
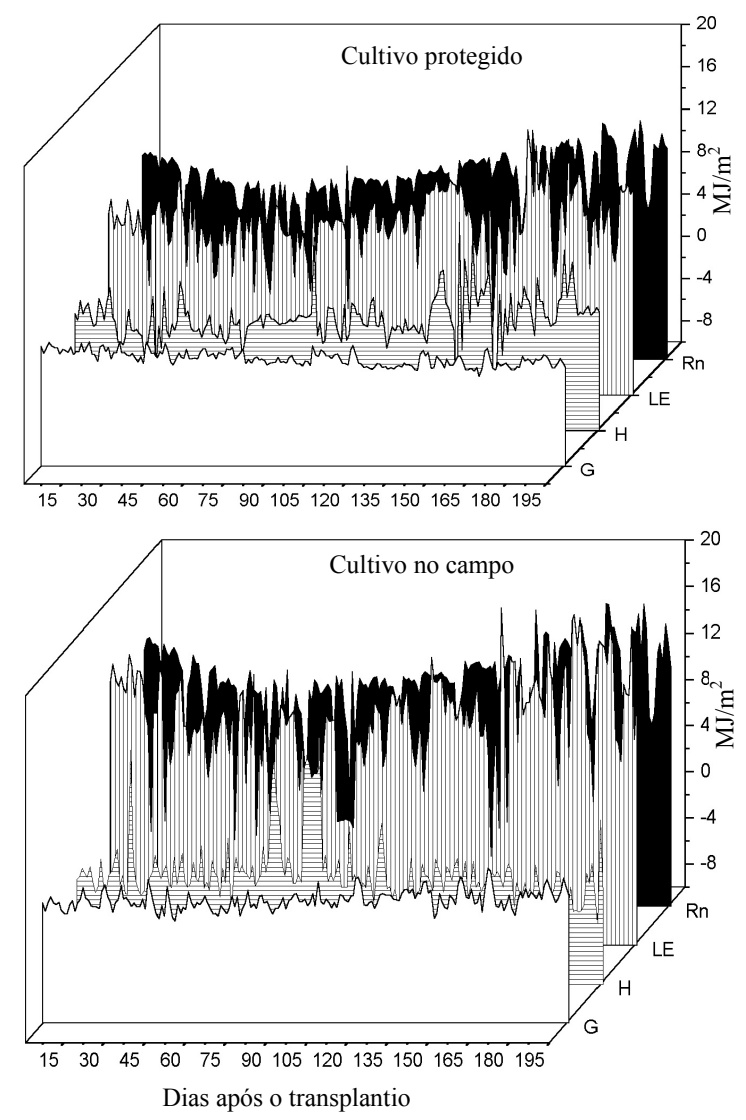

Figura 2. Variação da radiação líquida (Rn), fluxo de calor latente (LE), fluxo de calor sensível (H) e fluxo de calor no solo (G), em cultivo protegido e de campo, durante 195 dias após o transplantio da cultura do pimentão. tegido a atmosfera se encontrava mais aquecida que a cultura (Tabela 2 e Figura 2).

Houve, em algumas ocasiões, a diminuição de todas as componentes do balanço de energia, decorrente da acentuada redução da energia incidente no sistema, em ambos os cultivos. É importante notar que a variação da radiação solar global depende da época do ano, ou seja, declinação do Sol, mostrando-se, em função disto, que houve um decréscimo da quantidade de radiação solar global até os 100 DAT e após um aumento considerável, em ambos os cultivos, com exceção dos dias nublados (Figura 2).

O fluxo de calor latente equivalente em $\mathrm{mm}$ (ET) encontrado no cultivo protegido foi de $509,60 \mathrm{~mm} /$ ciclo, e no cultivo de campo foi de $741,11 \mathrm{~mm} /$ ciclo. Houve, portanto, um aumento de $45,43 \%$ no cultivo protegido em relação ao cultivo de campo, mostrando que na condição de cultivo protegido o calor cedido para a evaporação foi menor (Tabela 3). Este resultado está associado à opacidade parcial da cobertura de plástico transparente que reduziu a transmissividade da radiação solar global, e à redução da ação dos ventos nesse cultivo, os quais são os principais fatores que interferem na demanda evaporativa da atmosfera, conforme Montero et al. (1985). Esse porcentual também foi encontrado por Montero et al. (1985), Martins (1992), Stanghellini (1993) e Farias et al. (1994).

Na relação entre Y $(\mathrm{LE}+\mathrm{H})$ e $X(\mathrm{Rn}-\mathrm{G})$ no cultivo protegido $(\mathrm{Y}=0,9921 \mathrm{X})$, o $\mathrm{R}^{2}$ foi de 0,9913 enquanto no cultivo de campo $(Y=1,0002 X), o R^{2}$ foi de 0,9905 , o que indica validade das estimativas de $\mathrm{LE}$ e $\mathrm{H}$ em relação aos dois cultivos. A partir dessa relação (LE+H/Rn-G), os fluxos de calor latente e sensível apresentaram uma tendência de subestimativa dos seus valores em torno de $0,79 \%$ no cultivo protegido, e uma tendência de superestimativa dos seus valores em torno de $0,02 \%$ no cultivo a campo, como indica o coeficiente angular (b) de cada correlação.

A eficiência do uso da água para o cultivo protegido foi maior $\left(0,018 \mathrm{~kg} / \mathrm{m}^{2} / \mathrm{mm} /\right.$ ciclo $)$ do que no cultivo no campo $\left(0,009 \mathrm{~kg} / \mathrm{m}^{2} / \mathrm{mm} /\right.$ ciclo), pois o cultivo protegido apresentou maior produtividade de frutos para um menor consumo de água em milímetros, com um aumento de $100 \%$ na eficiência do uso da água (Tabela 3). 
Tabela 3. Fluxo de calor latente (ET), acumulado ao final do ciclo e por dia, produtividade e eficiência do uso da água (eua) ao longo do ciclo da cultura de pimentão.

\begin{tabular}{|c|c|c|c|c|}
\hline \multirow[t]{2}{*}{ Cultivo } & \multicolumn{2}{|c|}{$\mathrm{ET}(\mathrm{mm})$} & \multirow{2}{*}{$\begin{array}{c}\text { Produtividade } \\
\left(\mathrm{kg} / \mathrm{m}^{2} / \text { ciclo }\right)\end{array}$} & \multirow{2}{*}{$\begin{array}{c}\text { eua } \\
\left(\mathrm{kg} / \mathrm{m}^{2} / \mathrm{mm} / \text { ciclo }\right)\end{array}$} \\
\hline & (ciclo) & (dia) & & \\
\hline Protegido & 509,60 & 2,60 & 9,29 & 0,018 \\
\hline Campo & 741,11 & 3,78 & 6,66 & 0,009 \\
\hline $\mathrm{F}$ & - & $13,34^{* *}$ & $9,34^{* *}$ & $5,71^{*}$ \\
\hline CV (\%) & - & 26,07 & 44,84 & 64,51 \\
\hline
\end{tabular}

* e **Significativo a $5 \%$ e a $1 \%$ de probabilidade, respectivamente.

\section{Conclusões}

1. O cultivo protegido, apesar de receber menor quantidade de radiação solar global, é mais eficiente na conversão da radiação líquida disponível em matéria seca total e na produtividade de frutos na cultura de pimentão, em relação ao cultivo no campo.

2. No balanço de energia, o cultivo protegido apresenta menor quantidade de radiação líquida disponível, e com isso, menores perdas de energia, tanto na evaporação da água quanto no aquecimento do ar próximo à superfície, com conseqüente economia de água e condições mais favoráveis para o crescimento e desenvolvimento da cultura do pimentão.

3. A estimativa do fluxo de calor latente equivalente em $\mathrm{mm}$ através do balanço de energia para o manejo de água, absorvidos ao longo do ciclo da cultura de pimentão, é pertinente, pois as correlações entre $(\mathrm{LE}+\mathrm{H})$ e $(\mathrm{Rn}-\mathrm{G})$ indicam a validade das estimativas de $\mathrm{LE}$ e $\mathrm{H}$ de ambos os cultivos.

\section{Referências}

ALFONSI, R. R.; SANTOS FILHO, B. G.; PEDRO JÚNIOR, M. J.; BRUNINI, O.; CAMARGO, M. B. P. Balanço de energia em milho. Pesquisa Agropecuária Brasileira, Brasília, v. 21, n. 12, p. 1233-1235, dez. 1986.

ALVES, A. V.; AZEVEDO, P. V.; SILVA, B. B. Balanço de energia e refletância de um cultivo de melão. Revista Brasileira de Agrometeorologia, Santa Maria, v. 6, n. 2, p. 139-146, 1998.

ÁVILA NETTO, J.; AZEVEDO, P. V. de; SILVA, B. B. da; SOARES, J. M.; TEIXEIRA, A. H. de C. Balanço de energia sobre um cultivo de videira. In: CONGRESSO BRASILEIRO DE AGROMETEOROLOGIA, 11.; REU-
NIÃO LATINO-AMERICANA DE AGROMETEOROLOGIA, 2., 1999, Florianópolis. Anais... Florianópolis: Epagri, 1999. 1 CD-ROM.

BERGAMASCHI, H.; OMETTO, J. C.; VIEIRA, H. J.; ANGELOCCI, L. R.; LIBARDI, P. L. Deficiência hídrica de feijoeiro. II. Balanço de energia. Pesquisa Agropecuária Brasileira, Brasília, v. 23, n. 7, p. 745-757, jul. 1988.

BOWEN, I. S. The ratio of heat losses by conduction and by evaporation from any water surface. Physical Review, New York, v. 27, p. 779-787, 1926.

CAIXETA, T. J. Irrigação nas culturas de pimentão e pimenta. Informe Agropecuário, Belo Horizonte, v. 10, n. 113, p. 35-39, 1984.

CASALI, V. W. D.; COUTO, F. A. A. Origem e botânica de Capsicum. Informe Agropecuário, Belo Horizonte, v. 10 , n. 113 , p. $8-10,1984$.

CUNHA, A. R. da. Parâmetros agrometeorológicos de cultura de pimentão (Capsicum annuum L.) em ambientes protegido e campo. 2001. 128 f. Tese (Doutorado) - Universidade Estadual Paulista, Botucatu.

CUNHA, A. R. da; KLOSOWSKI, E. S.; GALVANI, E.; ESCOBEDO, J. F.; MARTINS, D. Classificação climática para o Município de Botucatu, SP, segundo Köppen. In: SIMPÓSIO EM ENERGIA NA AGRICULTURA, 1., 1999, Botucatu. Anais... Botucatu: Unesp, 1999, p. 487-491.

CUNHA, G. R.; BERGAMASCHI, H. Balanço de energia em alfafa. Revista Brasileira de Agrometeorologia, Santa Maria, v. 2, p. 9-16, 1994.

CUNHA, G. R.; BERGAMASCHI, H.; BERLATO, M. A.; MATZENAUER, R. Balanço de energia em cultivo de milho. Revista Brasileira de Agrometeorologia, Santa Maria, v. 4, n. 1, p. 1-14, 1996. 
DOORENBOS, J.; KASSAN, A. H. Efeito da água no rendimento das culturas. Tradução de $H$. R. Gheyi, A. A. de Souza, F. A. V. Damasceno, J. F. de Medeiros. Campina Grande: UFBP, 1994. 306 p. (FAO. Estudos de Irrigação e Drenagem, 33).

FARIA JÚNIOR, M. J. A. Avaliação de diferentes arquiteturas de estufas, coberturas do solo com filme plástico, em híbridos de pimentão (Capsicum annuиm L.). 1997. 102 f. Tese (Doutorado) - Universidade Estadual Paulista, Jaboticabal.

FARIAS, J. R. B.; BERGAMASCHI, H.; MARTINS, S. R. Evapotranspiração no interior de estufas plásticas. Revista Brasileira de Agrometeorologia, Santa Maria, v. 2, p. 17-22, 1994.

FONTANA, D. C.; BERLATO, M. A.; BERGAMASCHI, H. Balanço de energia em soja irrigada e não irrigada. Pesquisa Agropecuária Brasileira, Brasília, v. 26, n. 3, p. 403-410, mar. 1991.

INSTITUTO DE ECONOMIA AGRÍCOLA (São Paulo, SP). Tabela 2: estatísticas da produção vegetal, por produto, Estado de São Paulo, 2000. Série Informações Estatísticas da Agricultura, São Paulo, v. 12, n. 1, p. 20, 2001.

LEMON, E.; STEWART, D. W.; SHAWCROFT, R. W. The sun's work in a cornfield. Science, Washington, v. 174, p. 371-378, 1971.

MARTINS, G. Uso de casa de vegetação com cobertura plástica na tomaticultura de verão. 1992. $65 \mathrm{f}$. Tese (Doutorado) - Universidade Estadual Paulista, Jaboticabal.

MONTERO, J. I.; CASTILlA, N.; RAVÉ, E. G. de; BRETONES, F. Climate under plastic in the Almeria. Acta Horticulturae, Leuven, n. 170, p. 227-234, 1985.

PANELO, M. Adaptabilidad de cultivares de pimiento a condiciones de cultivo protegido. Horticultura Brasileira, Brasília, v. 13, n. 1, p. 101, 1995.
SANTOS, R. F.; RICIERI, R. P.; KLAR, A. E.; KRUGER, F. C. Comportamento de altura de planta de dois híbridos de pimentão cultivado na estufa e a campo. In: CONGRESSO BRASILEIRO DE AGROMETEOROLOGIA, 11.; REUNIÃO LATINO-AMERICANA DE AGROMETEOROLOGIA, 2., 1999, Florianópolis. Anais... Florianópolis: Epagri, 1999. 1 CD-ROM.

SILVA, F. C.; FURLAN, R. A.; FOLEGATTI, M. V. Estimativas de densidade de fluxo de calor sensível e latente através do método da razão de Bowen. In: CONGRESSO BRASILEIRO DE AGROMETEOROLOGIA, 11.; REUNIÃO LATINO-AMERICANA DE AGROMETEOROLOGIA, 2., 1999, Florianópolis. Anais... Florianópolis: Epagri, 1999. 1 CD-ROM.

SOUZA, J. L. Saldo radiômetro com termopilha de filme fino e aplicação no balanço de radiação e energia em cultivo de feijão-vagem (Phaseolus vulgaris L.) em casa-de-vegetação com cobertura de polietileno. 1996. 172 f. Tese (Doutorado) - Universidade Estadual Paulista, Botucatu.

STANGHELLINI, C. Evapotranspiration in greenhouse with special reference to Mediterranean conditions. Acta Horticulturae, Leuven, n. 335, p. 296-304, 1993.

TEODORO, R. E. F. Efeito da irrigação no crescimento e produção do pimentão (Capsicum annuum L.) conduzido em casa de vegetação e em condições de campo. 1986. 67 f. Dissertação (Mestrado) - Escola Superior de Agricultura Luiz de Queiroz, Piracicaba.

TIVELLI, S. W. Sistemas de cultivo na cultura do pimentão (Capsicum annuum L.) vermelho em ambiente protegido. 1999. $157 \mathrm{f}$. Tese (Doutorado) - Universidade Estadual Paulista, Botucatu.

VILLA NOVA, N. A. Estudos sobre o balanço de energia em cultura de arroz. 1973. 77 f. Tese (Livre docência) - Escola Superior de Agricultura Luiz de Queiroz, Piracicaba. 